\title{
Improving end-of-life care for people with dementia ${ }^{\dagger}$
}

\author{
Elizabeth L. Sampson, Alistair Burns and Mike Richards
}

\begin{abstract}
Summary
One in three adults over the age of 60 years will die with dementia. Most will have complex physical and psychological needs. Despite this, many people with dementia receive poor-quality end-of-life care. Recent government strategies have highlighted the
\end{abstract}

importance of improved coordination and provision of services.

Declaration of interest

None.
Liz Sampson (pictured) is a clinical senior lecturer at University College London, in a post funded by Marie Curie Cancer Care, and a consultant psychiatrist at Barnet Enfield and Haringey Mental Health Trust. Alistair Burns is the National Clinical Director for dementia in England, professor of old age psychiatry at the University of Manchester and a consultant psychiatrist at the Manchester Mental Health and Social Care Trust. Mike Richards is National Clinical Director for Cancer and End of Life Care at the Department of Health and led the development of the End of Life Care Strategy.

Today approximately 750000 people in the UK have dementia; by 2025 this will have increased to over 1 million. Perhaps an even more sobering fact is that one in three people over the age of 60 will die with dementia. ${ }^{1}$ The paper in this month's Journal by Lawrence et al aims to define good end-of-life care for people with dementia and identify how this can be delivered across a range of care settings. $^{2}$

\section{Why do people with dementia experience poor end-of-life care?}

Recent epidemiological studies have demonstrated significantly increased mortality rates in people with dementia. A study of a UK population screened for dementia gave a median survival time from diagnosis of 4.1 years. ${ }^{3}$ In a primary-care-based study, where the illness may be diagnosed at a much later stage, median survival times were 6.7 years in those diagnosed at age 60-69, falling to 1.9 years for those diagnosed at age 90 or over. ${ }^{4}$

A US study of care-home residents with advanced dementia revealed an even shorter median survival of 1.3 years, a life expectancy similar to that of metastatic breast cancer. ${ }^{5}$ Medical and nursing home staff consistently overestimate prognosis in advanced dementia; at nursing home admission only $1.1 \%$ of residents were thought to have a life expectancy of less than 6 months; however, $71 \%$ died within that period. ${ }^{6}$ In addition, there is a poor understanding of the pathophysiology of dementia among professionals. ${ }^{7}$ Thus, people with dementia, particularly those in the advanced stages, may experience poor end-of-life care because they are often not perceived to have a terminal illness, despite the fact that they are often bed bound, doubly incontinent and unable to communicate. Health and social care services may not be optimally configured to meet their complex needs.

\section{What are the end-of-life care needs of people with dementia and their families?}

In terms of physical problems, people with advanced dementia suffer a range of symptoms, similar to those found in the terminal stages of cancer, for example pain and dyspnoea. Many of these symptoms remain poorly detected and often go untreated. ${ }^{8}$ Pressure sores, agitation and eating problems (i.e. difficulty swallowing or anorexia) are very common. A study comparing symptoms experienced by people dying with dementia compared with those with cancer showed that the symptom burden between the two groups was comparable; in particular $64 \%$ of patients with dementia experienced pain and $57 \%$ loss of appetite. The healthcare needs of both groups were also similar. ${ }^{9}$ People with advanced dementia are often immobile, bed bound, at increased risk of aspiration and have impaired immunological function leaving them more at risk of pneumonia, urinary and other infections. These often lead to futile and distressing admissions to acute hospitals and are the commonest cause of death.

Numerous studies have highlighted how there is a failure to adopt a palliative or supportive approach to people with dementia and how inappropriate interventions are used. In contrast to those with cancer and other advanced chronic disease, most people with severe dementia lack the capacity required to make decisions about their care and treatment. This has a profound impact on providing the vital components of good end-of-life and person-centred care.

Support for carers, both during a person's illness and after their death, is a key aspect of the national Dementia and End of Life Care Strategies for England (see Appendix). There has been little research on carers of people with advanced dementia and their experiences of caring at the end of life; these may differ in important features from caring for those with other terminal diseases. Carers and family members of people with dementia often suffer significant levels of distress, burden and in particular 'anticipatory' or 'pre-death' grief. The unpredictable nature of disease progression as well as personality changes, behavioural and psychological symptoms of dementia add to this. Carers are frequently expected to act as 'proxies' and may have to make difficult and emotionally demanding choices at the end of life, for example, regarding parenteral feeding and resuscitation.

\section{How can we improve the provision of good-quality end-of-life care to people with dementia?}

The World Health Organization defines palliative care as: 'The active, total care of patients whose disease is not responsive to 
curative treatment. Control of pain, of other symptoms, and of psychological, social and spiritual problems is paramount. The goal of palliative care is achievement of the best quality of life for patients and their families. ${ }^{10}$

It has been suggested that people with dementia are denied access to hospice care, which is widely regarded as a gold standard. However, it could be argued that hospices provide specialist palliative care and that they should focus on cases of specialist need. Most of the symptoms experienced by people with dementia at the end of life, such as pain, pressure sores or difficulties swallowing, do not require specialist palliative care intervention but good-quality basic care. It is vital, as Lawrence et al state, that care is more than just 'task focused' and that staff should go 'beyond' this. ${ }^{2}$ Most care professionals are keen to attend to the person with dementia's social, emotional and cultural needs but, as an inquiry by the UK Equality and Human Rights Commission has found, time constraints and high levels of staff turnover pose a challenge to providing even a basic standard of care. ${ }^{11}$

Directly transferring interventions and models of care from the cancer field may not be appropriate. In contrast to the cancer workforce, most end-of-life care for people with dementia is provided by relatively inexperienced care assistants in residential settings and by social services carers. Training and educational programmes on end-of-life care for nursing home staff are effective in improving knowledge and increasing satisfaction with end-of-life care in bereaved family members. ${ }^{12}$

Advance care planning is a cornerstone of the Government's end-of-life care strategy in England and is often promoted as a possible way of improving choice and autonomy for people with dementia. However, it may be necessary to do this in the earlier stages of dementia when a person is still able to make decisions and express their values and preferences. There is a paucity of information on whether advance care plans, made around the time of a diagnosis of dementia, actually change outcomes or improve the 'quality of death'. Lawrence et al highlight some key concerns regarding this including the reluctance of staff to assume the responsibility for discussing advance care planning and concerns that a person with early dementia may adapt and undergo a 'response shift' in their view of what constitutes a good quality of life as the disease progresses. ${ }^{2}$

In terms of specific interventions for people with dementia, the evidence base is somewhat limited, particularly when compared with research on palliative care for people dying from cancer. Systematic reviews have identified how care mainly focuses on specific interventions such as 'fever management policies', pain control or the withdrawal of care (i.e. not prescribing antibiotics), rather than a more active palliative mode. ${ }^{13}$ Good person-centred care requires a more rounded approach and a number of multicomponent complex interventions and pathways have been developed that may improve the quality of end-of-life care in the acute hospital and in the community. These include the National Institute for Health and Clinical Excellence (NICE) guidelines for dementia ${ }^{14}$ that include some recommendations, in particular the use of the Gold Standards Framework (see Appendix) and the Liverpool Care Pathway for the dying.

\section{Conclusions}

Some people felt that the National Dementia Strategy contained inadequate reference to end-of-life care and that the End of Life Care Strategy should have made more acknowledgement of the rising numbers of people who will die with dementia (see Appendix). The focus of many psychiatric services on a 'recovery model' and the important emphasis on early detection and management of dementia may conflict with taking a more palliative approach. Policy guidance and end-of-life initiatives have multiplied over the past 5 years but these have not been underpinned by good-quality evidence on end-of-life care for people with dementia and their families. Research has tended to focus on people with advanced dementia and comparatively little is known about those in the earlier stages of dementia who may be dying from other chronic comorbid conditions, such as end-stage renal or respiratory failure, or cancer. It was therefore encouraging that the recent Ministerial Advisory Group on Dementia Research highlighted the need for more research on end-of-life care. ${ }^{15}$

New interventions or service models to improve care will have to be developed carefully, taking account of the wide range of settings in which people with dementia die, as well as cultural and staff factors, with due consideration of what may work best for whom and in what circumstances. In view of the increasing numbers who will require care as they die with dementia, interventions that are developed must also be cost-effective. The paper by Lawrence et al defines a good death with dementia as being free from pain and being surrounded by those who are close to the person with dementia; ${ }^{2}$ these are not highly technical or difficult goals but require cooperation, communication and good coordination by and between health and social care professionals.

\section{Elizabeth L. Sampson, MD, MRCPsych, UCL Mental Health Sciences Unit, London; Alistair Burns, MD, FRCPsych, University of Manchester, Manchester; Mike Richards, CBE, MD, FRCP, Department of Health, London, UK}

Correspondence: Elizabeth L. Sampson, Mental Health Sciences Unit, University College London Medical School, Rowland Hill Street, London NW3 2PF, UK. Email: e.sampson@ucl.ac.uk

First received 13 Jul 2011, final revision 29 Aug 2011, accepted 15 Sep 2011

\section{Appendix}

\section{Key guidelines and documents}

National Dementia Strategy:

www.dh.gov.uk/en/SocialCare/NationalDementiaStrategy/index.htm National End of Life Care Strategy:

www.endoflifecareforadults.nhs.uk/strategy/strategy

End of Life Care for People with Dementia: Commissioning Guide

(6 July 2010). National End of Life Care Programme/National Institute for Health and Clinical Excellence:

www.endoflifecareforadults.nhs.uk/publications/eolc-for-people-withdementia-commissioning-guide

Care towards the End of Life for People with Dementia:

An Online Resource Guide:

www.endoflifecareforadults.nhs.uk/publications/care-towards-the-end-

of-life-for-people-with-dementia/

Gold Standards Framework:

www.goldstandardsframework.org.uk

\section{References}

1 Brayne C, Gao L, Dewey M, Matthews FE, Medical Research Council Cognitive Function and Ageing Study Investigators. Dementia before death in ageing societies - the promise of prevention and the reality. PLOS Med 2006; 3, e397.

2 Lawrence V, Samsi K, Murray J, Harari D, Banerjee S. Dying well with dementia: qualitative examination of end-of-life care. Br J Psychiatry 2011; 199: 417-22.

3 Xie J, Brayne C, Matthews FE. Survival times in people with dementia: analysis from population based cohort study with 14 year follow-up. BMJ 2008; 336: 258-62.

4 Rait G, Walters K, Bottomley C, Petersen I, lliffe S, Nazareth I. Survival of people with clinical diagnosis of dementia in primary care: cohort study. BMJ 2010; 341: c3584. 
5 Mitchell SL, Teno JM, Kiely DK, Shaffer ML, Jones RN, Prigerson HG, et al. The clinical course of advanced dementia. N Engl J Med 2009; 361: 1529-38.

6 Mitchell SL, Kiely DK, Hamel MB. Dying with advanced dementia in the nursing home. Arch Intern Med 2004; 164: 321-6.

7 Thuné-Boyle ICV, Sampson EL, Jones L, Kings M, Lee DR, Blanchard MR. Challenges to improving end of life care of people with advanced dementia in the UK. Dementia, 2010; 9: 285-98.

8 Shega JW, Hougham GW, Stocking CB, Cox-Hayley D, Sachs GA. Management of noncancer pain in community-dwelling persons with dementia. J Am Geriatr Soc 2006; 54: 1892-7.

9 McCarthy M, Addington-Hall J, Altmann D. The experience of dying with dementia: a retrospective study. Int J Geriatr Psychiatry 1997; 12 404-9.

10 World Health Organization. Cancer Pain Relief and Palliative Care. Report of a WHO Expert Committee (Technical Report series, no. 804). WHO, 1990.
11 Equality and Human Rights Commission. Inquiry into home care of older people. Available at http://www.equalityhumanrights.com/legal-and-policy/ inquiries-and-assessments/inquiry-into-home-care-of-older-people/

12 Arcand $\mathrm{M}$, Monette J, Monette $\mathrm{M}$, Sourial N, Fournier L, Gore B, et al. Educating nursing home staff about the progression of dementia and the comfort care option: impact on family satisfaction with end-of-life care. J Am Med Dir Assoc 2009; 10: 50-5.

13 Sampson EL, Ritchie CW, Lai R, Raven PW, Blanchard MR. A systematic review of the scientific evidence for the efficacy of a palliative care approach in advanced dementia. Int Psychogeriatr 2005; 17: 31-40.

14 National Collaborating Centre for Mental Health. Dementia: A NICE-SCIE Guideline on Supporting People with Dementia and their Carers in Health and Social Care. British Psychological Society \& Gaskell, 2007

15 Department of Health. Ministerial Advisory Group on Dementia Research: Headline Report. Department of Health, 2011.
Psychiatry in the movies

\section{Batman and psychiatry}

\section{Joseph Kane}

'If you think Arkham's scary as a doctor, you should try it as a patient.'

Harley Quinn, Detective Comics, no. 83100

Since first appearing in Detective Comics in May 1939, Batman has become one of the most recognisable characters in 21st-century culture, spawning countless television series, video games, graphic novels and films. A frequently dark and psychological franchise, the Caped Crusader's battle to save Gotham City from a multitude of colourful enemies often takes place against the sinister backdrop of Arkham Asylum for the Criminally Insane, run by the sadistic Dr Jeremiah Arkham.

In addition to some of Batman's more infamous foes, the Joker, the Penguin and Two-Face, Arkham is home to a number of other characters displaying a variety of psychiatric presentations: Amygdala, who, after surgical removal of his namesake anatomical structure, exhibits Klüver-Bucy syndrome; and the Ventriloquist, a former gangster with dissociative identity disorder, to name but two. However, it is our hero's travails against doctors that expose the franchise's prevailing unfavourable attitude towards psychiatrists and asylums.

A relative newcomer to the Batman universe, Harley Quinn first appeared in 1992, her origins detailed in the graphic novel Mad Love (1994). Portrayed in different versions as an intern psychiatrist or psychoanalyst, Dr Harveen Quinzel volunteers to psychoanalyse Batman's greatest foe, the Joker, following his admission to Arkham, but soon falls in love with her patient. Manufacturing his escape and assuming the moniker Harley Quinn, she becomes his lover and sidekick: 'I found the Joker's psyche disturbing, his dementia alarming, and his charm irresistible!'.

Dr Jonathan Crane, the Scarecrow, is a corrupt 'expert in fear' who induces his victims' greatest fears through the administration of psychoactive substances, using a hessian sack as a disguise and gas mask. The role is played to chilling effect by Cillian Murphy in both Batman Begins (2006) and The Dark Knight (2008)

Although traditionally a minor character in the Batman canon, Dr Hugo Strange is one of Batman's oldest enemies, first appearing in 1940 (pre-dating Catwoman and the Joker by several months), and is expected to appear as a key character in The Dark Knight Rises, the last film in Christopher Nolan's trilogy. A corrupt Machiavellian professor of psychiatry, Strange performs barbaric experiments on his in-patients, brainwashes Gotham's citizens and blackmails his rich psychotherapy clients. In the Prey series of graphic novels (2000), Strange is recruited as a forensic psychiatrist to the Gotham City Police and through psychological profiling deduces Bruce Wayne as the Caped Crusader's alter ego.

In addition to its damning portrayal of psychiatrists, the series also contains tacit references to the anti-psychiatry movement. Alan Grant, author of Batman: The Last Arkham (1992), derived the name of serial killer Victor Zsasz from that of Thomas Szasz and many of the Joker's quips ('In a world as psychotic as this. . . any other response would be crazy!') are reminiscent of R. D. Laing's famous quote, 'Insanity is a sane response to an insane situation'. 